\title{
Prevalence of Anaplasmosis Caused by Anaplasma marginale in Cattle in and around Puducherry Region, India
}

\author{
B. Subramanian ${ }^{1 *}$, P. Vijayalakshmi ${ }^{1}$, S.S. Das ${ }^{2}$ and D. Selvi ${ }^{1}$ \\ ${ }^{1}$ Department of Veterinary Medicine, Teaching Veterinary Clinical Campus, Rajiv Gandhi \\ Institute of Veterinary Education and Research, Puducherry-605009, India \\ ${ }^{2}$ Department of Veterinary Parasitology, Rajiv Gandhi Institute of Veterinary Education and \\ Research, Puducherry-605009, India \\ *Corresponding author
}

\begin{abstract}
A B S T R A C T
Keywords

Prevalence,

Anaplasma marginale, Rhipicephalus appendiculatus, Cattle

Article Info

Accepted:

04 March 2018

Available Online:

10 April 2018

The present study was conducted in cattle brought to Large Animal Medicine Unit, Teaching Veterinary Clinical Campus, Rajiv Gandhi Institute of Veterinary Education and Research and Ambulatory clinic for treatment of various medical ailments from June 2017 to November 2017. Seventy three cases with clinical signs of pale to icteric mucous membrane and tick infestation were subjected for blood smear examination and Polymerase Chain Reaction (PCR). Out of these fifteen cattle were found positive for Anaplasma marginale infection either by blood smear and / by PCR, accounting to an overall prevalence of 20.55 percent The ticks collected from those animals were identified based on morphological features as Rhipicephalus appendiculatus.
\end{abstract}

\section{Introduction}

The genus Anaplasma, Rickettsiales: Anaplasmataceae are obligate intracellular etiological mediator distressing tick borne diseases in mammalian hosts (Dumler et al., 2001). They infect mature erythrocytes by an endocytic process and reproduction occurs by binary fission to produce 2-8 infective initial bodies which leave the cell by exocytosis to infect other erythrocytes (Radostits et al., 2010). Of the three erythrocytic Anaplasma spp., two infects cattle, namely Anaplasma marginale and Anaplasma centrale whereas Anaplasmaovis infects sheep and goat was also well recognized (Lestoquard, 1924).

Clinical anaplasmosis was first recorded in cattle from the State of Odisha, India by Patnaik (1963). Later, In Canada Boulanger et al., (1971) stated the first occurrence of anaplasmosis arose in the year 1971. Office of the International Epizootics (2003) stated that anaplasmosis is presently categorized in List B of the Terrestrial Animal Health Code due to its socio-economic status and consequence in 
terms of restrictions in the global trade of animals and animal products. Predominance of A. marginale was found to be $48.75 \%$ by molecular procedures in seven districts of Punjab, India (Ashuma et al., 2013). OIE (2013) in North India, 20 outbreaks of anaplasmosis arose during the period of January to June 2013, out of which five were stated from Jammu and Kashmir, six from West Bengal and nine from Punjab, signifying the hazard stood on livestock by the disease.

Anaplasmosis is reflected as one of the top 10 economically significant rickettsial diseases distressing ruminants in India (Srikant and Gaurav, 2014). Abdela et al., (2017) reported prevalence of bovine anaplasmosis as $6.1 \%$ by Giemsa staining in Jimma region of Ethiopia. Twenty different species of ticks transmitting anaplasma (Kocan et al., 2004), comprising of Hyalomma spp., Rhipicephalus spp., Boophilus spp., Ixodes spp. and Demacentor spp.

Though Boophilus microplus is found to be the chief transmitting agent (Aubry and Geale, 2011). Mechanical spread is probable by biting flies or blood-contaminated fomites (Brayton et al., 2005). The cause of infection is constantly the blood of an infested animal. Predominance of anaplasmosis is found greater in warm and moist weather accompanying with the plenty of vector (Kocan et al., 2004).

\section{Materials and Methods}

Cattle brought to Large Animal Medicine Unit, Teaching Veterinary Clinical Campus, Rajiv Gandhi Institute of Veterinary Education and Research and Ambulatory clinic for treatment of various medical ailments in that seventy three cases with clinical signs of pale to icteric mucous membrane and tick infestation were subjected for blood smear examination and PCR.
A systematic clinical examination was carried out and ticks, if existing were collected and exposed for identification of the species. The ticks collected were immediately processed for identification with DPX mount and were observed under light microscope with $4 \mathrm{x}$ magnification.

\section{Results and Discussion}

Seventy three cases with clinical findings of pale to icteric mucous membrane and tick infestation were subjected for blood smear examination and PCR. Out of these, 15 were found positive for $A$. marginale infection either by blood smear and or by PCR. The occurrence of Anaplasmosis in cattle in Puducherry region is $20.55 \%$ among the tickborne diseases.

PCR was found to be more sensitive for the detection of A. marginale, out of 73 anaplasmosis suspected samples, 15 were found to be positive for A. marginale (Fig. 1) while only three turned positive by blood smear examination.

Out of 15 cattle found positive for anaplasmosis, 10 cattle $(66.67 \%)$ were infested with ticks. The ticks collected from those animals were identified based on morphological features as Rhipicephalus appendiculatus (Fig. 2 and 3).

The prevalence of Anaplasmosis in cattle in Puducherry region was $20.55 \%$, this was compared with the incidence reports from different regions of India. Nair et al., (2013) reported $16.67 \%$ incidence in four districts of Kerala. An incidence of $22 \%$ anaplasmosis in Telangana was documented by Neena et al., (2017) while in Seemandhrathe incidence was reported to be $3.4 \%$. The ticks collected from the affected animals were identified based on morphological features as Rhipicephalus appendiculatus. 
Fig.1 Agarose gel electrophoresis of PCR product of Anaplasma marginale

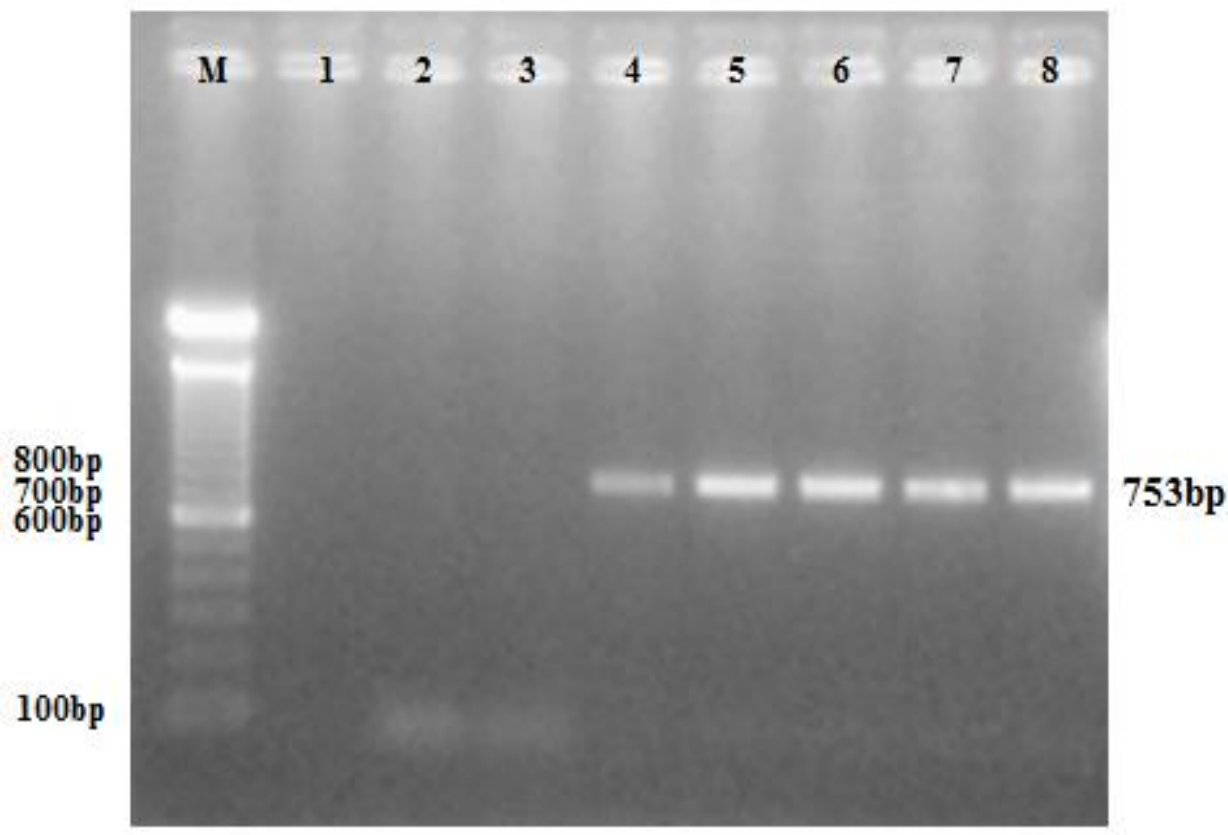

Lane M - 100bp DNA ladder; Lane 1 - Negative control; Lane 2 to 8-Samples

Fig.2 and Fig.3 Rhipicephalus appendiculatus (DPX mount - 4X)

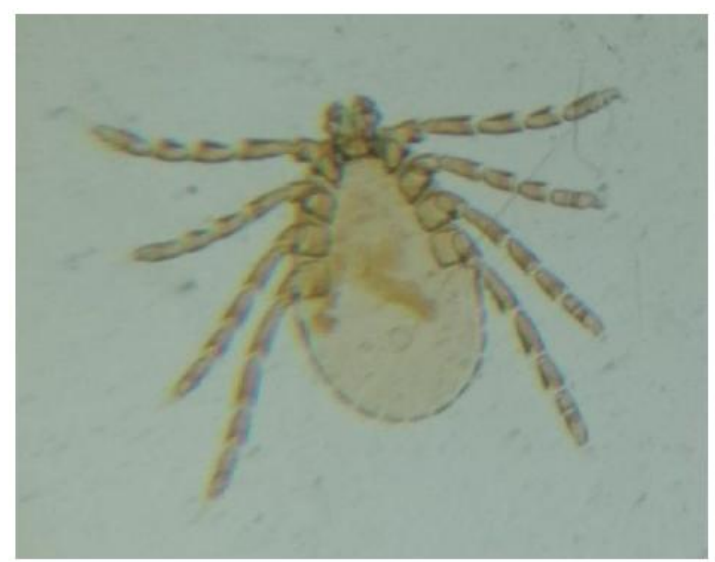

This was in agreement with Yamada et al., (2008) who stated that A. marginale was transmitted by Rhipicephalus appendiculatus. However Robert et al., (2009) stated that $R$. appendiculatus showed comparatively low finding rate / transmission for A. marginale infection. Fyumagwa et al., (2009) in his study proposes that this tick species is possibly infected by many more of the

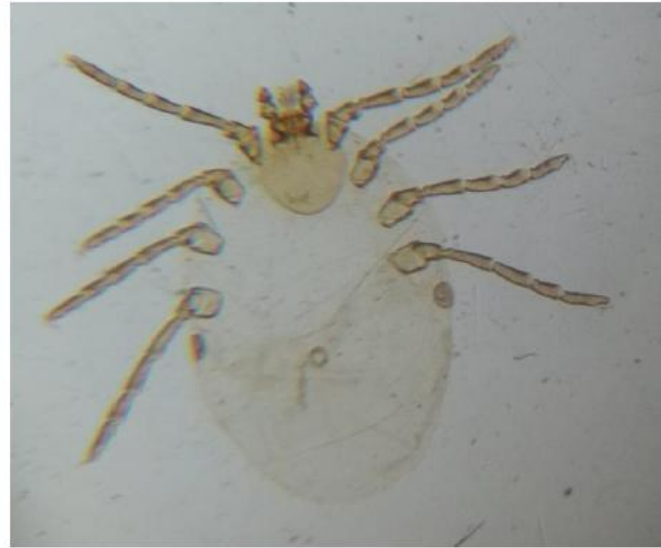

recognized tick-borne pathogens than it was believed before and is the most significant tick species in transmitting a extensive range of tick-borne diseases in eastern, central and southern Africa where the tick species is widespread. However, no studies have evaluated their competence in the transmission of Anaplasma marginale in Puducherry region. 


\section{Acknowledgments}

The authors are grateful to the Dean, Head, Department of Veterinary Medicine and Head, Department of Veterinary Parasitology, Rajiv Gandhi Institute of Veterinary Education and Research, Puducherry for providing necessary facilities for the work.

\section{References}

Abdela, N., Ibrahim, N. and Begna, F. (2017) Prevalence, risk factors and vectors identification of bovine anaplasmosis and babesiosis in and around Jimma town, Southwestern Ethiopia, ActaTropica, 177: 9-18

Ashuma, Amrita, S., Lachhman, D.S., Paramjit, K., Mandeep, S.B., Balwinder, K.B. and Prayag, D.J. (2013). Prevalence and haemato-biochemical profile of $A$. marginale infection in dairy animals of Punjab (India), Asian Pacific J. Tropical Medicine, pp139144

Aubry, P and Geale, D.W. (2011) A review of bovine anaplasmosis. Transbound. Emerg. Dis., 58: 1-30

Boulanger, P., Ruckerbauer, G.M., Bannister, G.L., McKay, R.R. and Peter, N.Y. (1971) Anaplasmosis: control of the first outbreak in Canada by serologic identification and slaughter. Can. J. Comp. Med.35: 429-432

Brayton, K.A., Kappmeyer, L.S., Herndon, D.R., Dark, M.J., Tibbals, D.L. and Palmer, G.H. (2005). Complete genome sequencing of $A$. marginale reveals that the surface is skewed to two super families of outer membrane proteins. Proc National Acad Sci. 102:844-849

Dumler, J., Barbet, A., Bekker, C., Dasch, G., Palmer, G., Ray, S., Rikihisa, Y. and Rurangirwa, F. (2001) Reorganization of genera in the families Rickettsiaceae and Anaplasmataceae in the order
Rickettsiales: unification of some species of Ehrlichia with Anaplasma, Cowdria with Ehrlichia and Ehrlichia with Neorickettsia, descriptions of six new species combinations and designation of Ehrlichiaequi and HGE agent as subjective synonyms of Ehrlichia phagocytophila. Int $J$ Syst Evol Microbiol, 51:2145-2165

Fyumagwa, R.D., Simmler, P., Meli, M.L., Hoare, R., Hofmann-Lehmann, R. and Lutz, H. (2009) Prevalence of Anaplasma marginale in different tick species from Ngorongoro Crater, Tanzania. Veterinary Parasitology, 161: 154-157

Kocan, K.M., De La Fuente, J., Blouin, E.F. and Garica-Garcia, J.C. (2004) A. marginale (Rickettsiales: Anaplasmataceae): Recent advances in defining host-pathogen adaptations of a tick-borne rickettsia. Parasitology, 129: 285-300

Lestoquard, F. (1924) Deuxieme note sur les piroplasmoses du mouton en Algerie. Anaplasmose: Anaplasmaovis nov. sp. Bull Soc Path Exot, 17: 784 - 787

Nair, A.S., Ravindran, R., Lakshmanan, B., Sreekumar, C., Kumar, S.S., Remya Raju, Tresamol, P.V., Vimalkumar, M.B. and Saseendranath, M.R (2013) Bovine carriers of $A$. marginale and $A$. bovis in South India. Tropical Biomedicine, 30: 105-112

Neena, G., Vasundhra, B. and Paresh, S. (2017) Phylogenetic relationship and genotypic variability in $A$. marginale strains causing anaplasmosis in India. Infection, Genetics and Evolution.48:71-75

OIE (2013) http://www.oie.int/wahis_2/ public/wahid.php/Diseaseinformation/st atusdetail

OIE (Office International des Epizooties Web Site), (2003).Terrestrial Animal Health 
Code. Bovine Anaplasmosis, Chapter 2.3.7, accessed on July 28

Patnaik, M.M. (1963).A note on bovine anaplasmosis. Indian Vet J, 40: 655 657

Radostits, O.M., Gay, C.C., Hinchcliff, K.W. and Constable, P.D. 2010. Veterinary Medicine. A textbook of the diseases of Cattle, Horses, Sheep, Pigs and Goats $10^{\text {th }}$ ed., Book power Saunders, London, New York, pp 1455 -1459

Robert, D.F., Pascale, S., Marina, L.M., Richard, H., Regina, H.L. and Hans, L. (2009) Prevalence of Anaplasma marginale in different tick species from
Ngorongoro Crater, Tanzania, Veterinary Parasitology, 161: 154-157

Srikant, G. and Gaurav, N. (2014) Problem of ticks and tick-borne diseases in India with special emphasis on progress in tick control research: A review. $J$ Vector Borne Dis.51:259-270

Yamada, S., Konnai, S., Imamura, S., Simuunza, M., Chembensofu, M., Chota, A., Nambota, A., Onuma, M. and Ohashi, K. (2008) PCR-based detection of blood parasites in cattle and adult Rhipicephalus appendiculatus ticks. Vet J.182: 352-355

\section{How to cite this article:}

Subramanian, B., P. Vijayalakshmi, S.S. Das and Selvi, D. 2018. Prevalence of Anaplasmosis Caused by Anaplasma marginale in Cattle in and around Puducherry Region, India. Int.J.Curr.Microbiol.App.Sci. 7(04): 189-193. doi: https://doi.org/10.20546/ijcmas.2018.704.020 